\title{
Mapeamento e análise do uso e ocupação do solo na bacia do Rio Vieira no município de Montes Claros/MG
}

\author{
Mapping and analysis of land use and occupation in the Vieira River watershed in the municipality of Montes \\ Claros/MG
}

\author{
Adriana Aparecida Moreira ${ }^{1}$ \\ Fernando Hiago Souza Fernandes ${ }^{2}$ \\ César Vinícius Mendes Nery ${ }^{3}$
}

\author{
${ }^{1}$ Programa de Pós-Graduação em Sensoriamento Remoto-Universidade Federal do Rio Grande do Sul \\ ${ }^{2}$ Bolsista de Desenvolvimento Tecnológico Industrial do CNPq \\ ${ }^{3}$ Professor Mestre das Faculdades de Ciências Exatas e Tecnológicas Santo Agostinho \\ moreiradriana00@gmail.com, hiagosf@hotmail.com,cvmn@hotmail.com
}

\begin{abstract}
RESUMO - Com o uso das geotecnologias é possível identificar e quantificar as mudanças no espaço físico ao longo do tempo. No presente trabalho buscou-se avaliar as mudanças do uso e ocupação do solo na Bacia do Rio Vieira entre um espaço temporal de três anos. Para a verificação das alterações ocorridas na Bacia do Rio Vieira entre 2009 e 2012 , foi utilizado o mapeamento do ano de 2009, realizado por Leite et al. (2011) e mesma base metodológica para elaboração do mapeamento para o ano de 2012, com classificação supervisionada, pixel a pixel, algoritmo de máxima verossimilhança (MAXVER) e limiar de aceitação de 99,99\%. Foram definidas as seguintes classes; área urbana, cultura agrícola, mineração, recursos hídricos, pastagem, silvicultura, vegetação natural e outros. Dentre as mudanças sofridas por essa bacia no intervalo de três anos, pode-se perceber aumento de uso do solo para atividade minerária e de silvicultura, além de contínuo uso para pastagem, uma vez que a região tem a agropecuária como uma atividade economicamente representativa.
\end{abstract}

Palavras-chave: Máxima Verossimilhança, Uso do Solo, Geotecnologia.

ABSTRACT - With the use of geotechnology is possible to identify and quantify changes in physical space over time. In the present study sought to assess changes in the use and occupation of the ground in Vieira River basin between a timeline of three years. For the verification of changes in Vieira River Basin between 2009 and 2012, was used the mapping of 2009, created by Leite et al. (2011) and the same methodological basis for the elaboration of mapping for the year 2012, with supervised classification, pixel for pixel, maximum likelihood algorithm (MAXVER) and 99.99\% acceptance threshold. The following classes are defined; urban area, agricultural culture, mining, water resources, forestry, grazing, natural vegetation and others. Among the changes suffered by this basin in the range of three years, one can notice increase of land use for mining and forestry activity, in addition to continuous use for grazing, once the region's agriculture as an economic activity.

Keywords: Maximum Likelihood, Land Use, Geotechnology.

\section{INTRODUÇÃ̃O}

As modificações na paisagem decorrentes das atividades humanas podem provocar desequilíbrio nos ecossistemas, conseqüentemente na quantidade e qualidade dos recursos naturais e no bem estar das populações. A partir de uma visão holística da paisagem e a necessidade de compreensão das relações existentes entre o homem, a natureza e a sociedade, foram criadas novas visões e enfoques para as pesquisas voltadas ao meio ambiente.

Para uso sustentável dos recursos naturais, torna-se necessário um gerenciamento adequado. A Lei Federal $\mathrm{n}^{\circ}$ 9.433/97 (BRASIL, 1997), instituiu como unidade básica de gestão, a bacia hidrográfica, uma vez que nela é possível mensurar os impactos ambientais e corrigi-los dentro desse limite. Analisando os processos que causam impactos ambientais, e baseados na utilização do solo, os gestores podem propor soluções capazes para as situações encontradas.

Na Bacia Hidrográfica do Rio Vieira está inserido o município de Montes Claros e esta possui valor vultoso para a região, em função de parte do abastecimento público de água da maior cidade do Norte de Minas ser proveniente dos recursos hídricos dessa bacia e pelas características de clima semiárido da região. Neste sentido, torna-se necessário um monitoramento das mudanças ocorridas nesta bacia, devido a estar localizado um município de grande porte e importância econômica em uma região semi-árida.

As técnicas de Sensoriamento Remoto tornaram-se importantes ferramentas para os estudos voltados à análise das modificações ambientais. $\mathrm{O}$ mapeamento do uso e cobertura do solo é hoje uma ferramenta importante, permitindo a obtenção de informações que fomentam a 
construção de cenários ambientais e indicadores, como subsídios de avaliação da capacidade de suporte ambiental, sendo este realizado por meio de técnicas de classificação digital de imagens, com a utilização de algoritmos classificadores.

Utilizando de classificação digital de imagens, objetiva-se com este trabalho o mapeamento do uso do solo na Bacia do Rio Vieira, em Montes Claros/MG para o ano de 2012, e realização de uma análise comparativa com o mapeamento do ano de 2009 realizado por Leite et al. (2011).

\section{REFERENCIAL TEÓRICO}

De acordo com Leite et al. (2011), nas últimas décadas a humanidade tem se preocupado com os problemas ambientais provocados pela exploração não sustentável dos recursos naturais. Segundo Philippi et al. (2004), o grande agente transformador do ambiente natural é o homem, pois há pelo menos 12 milênios este vem promovendo transformações e adaptações na paisagem natural, causando mudanças climáticas, geográficas e topográficas. De acordo com Dill (2007), uma vez que o homem não tem usado sua habilidade para manipular a terra com sabedoria e precaução necessárias, provoca a deterioração do meio, promovendo um cenário de desequilíbrio ambiental, em virtude do crescimento desordenado das cidades, o desmatamento de florestas, deterioração dos solos e um manejo inadequado das terras agrícolas.

A unidade de caracterização, diagnóstico, planejamento e gestão ambiental, para o desenvolvimento regional sustentável, deve ser a bacia hidrográfica (BRASIL, 1997), pois nesta os impactos ambientais podem ser mensurados e corrigidos mais facilmente dentro do seu limite.

Nas bacias, podem ser realizadas diferentes análises ambientais, com o intuito de obtenção de informações da atual situação local, proporcionando um gerenciamento adequado para a perenização dos recursos naturais ali existentes e imprescindíveis ao bem estar humano.

Com a utilização das técnicas de sensoriamento remoto, é possível analisar a natureza de uma forma mais ampla, pois os sentidos humanos são potencializados pelas novas tecnologias, possibilitando um raciocínio sobre as transformações ambientais de forma digital e em grande escala (PHILIPPI et al., 2004).

De acordo com Liu (2006), é possível identificar e classificar os diferentes tipos de uso do solo a partir de classificação de imagens digitais.

Florenzano (2011), afirma que, as técnicas de classificação de imagens digitais objetivam o reconhecimento automático de feições, em função de um critério determinado de decisão, podendo ser agrupado em classes aquelas feições ou objetos que apresentam semelhança em suas respostas espectrais, tendo como resultado, um mapa temático, em que cada pixel ou agrupamentos de pixels da imagem são classificados em classes definidas pelo usuário.
Os métodos de classificação de imagens digitais estão agrupados em duas categorias; classificação supervisionada e classificação não supervisionada (LIU, 2006). A técnica de classificação supervisionada é aquela em que as classes são definidas a priori, ou seja, o analista é quem fornece as amostras de treinamento das classes espectralmente representativas e identifica estas como pertencentes a uma classe de interesse, posteriormente, utiliza-se um algoritmo para localizar as demais classes na imagem a ser classificada, baseado em uma regra de estatística pré-definida (FLORENZANO, 2011). Em contra partida na classificação não supervisionada, as classes são definidas a posteriori, o algoritmo procurará automaticamente identificar o comportamento espectral dos alvos e define o número de classes a serem discriminados na imagem (FITZ, 2008).

A classificação pode ser do tipo pixel a pixel ou por regiões. Na técnica de classificação pixel a pixel utiliza-se a informação espectral isolada de cada pixel para a identificação das regiões homogêneas, já na técnica de classificação por regiões, é considerado a variabilidade espacial e a textura natural das feições dos agrupamentos de pixels (CASTANHEIRA, 2010; MARTE et al., 2011).

$\mathrm{O}$ algoritmo de classificação supervisionada pixel a pixel mais utilizado é o de máxima verossimilhança (MAXVER). Sendo que o método utilizado neste algoritmo consiste em classificar a imagem ponto a ponto considerando a ponderação das distâncias entre médias dos níveis digitais das classes utilizando parâmetros estatísticos (CUNHA, 2009).

Conforme Novo (2010), a avaliação da classificação, é um processo necessário que possibilita determinar a qualidade do mapa elaborado. A avaliação da classificação é realizada por meio de estatísticas, essas, visam verificar se os alvos estão atribuídos corretamente nas classes. A partir da matriz de confusão, é possível calcular os índices de avaliação, como o índice Kappa. (MARTE et al., 2011).

De acordo com Cunha (2009), o índice Kappa é comumente usado na avaliação de classificação, sendo considerado eficiente e seguro na avaliação da exatidão de mapeamentos. A eq. 1 apresenta o índice de Kappa.

$$
k=\frac{\mathbb{N} \sum x_{\mathrm{i}_{i}}-\sum \mathrm{X}_{\mathrm{i}+} \mathrm{x}_{+\tilde{\mathrm{I}}}}{\mathbb{N}^{2}-\sum \mathrm{X}_{\mathrm{i}+} \mathrm{X}_{+\mathrm{i}}}
$$

Onde:

$\mathrm{N}=$ número total de amostras;

$\sum X_{\mathrm{ii}}=$ soma do número das amostras corretas nas linhas e colunas;

$\mathrm{X}_{\mathrm{i}+=}$ soma linear; $\mathrm{X}_{+\mathrm{i}=}$ soma collinear

De acordo com Landis e Koch (1977), a Tab. 1 a seguir, apresenta os valores do índice Kappa variando de 0 a 1 e suas respectivas concordâncias. 
$\underline{\text { Tabela } 1 \text { - Valores de Índice Kappa. }}$

\begin{tabular}{cc}
\hline Índice Kappa & Concordância \\
\hline$<0$ & Sem concordância \\
0.00 a 0.19 & Pobre \\
0.20 a 0.39 & Fraca \\
0.40 a 0.59 & Moderada \\
0.60 a 0.79 & Forte \\
0.80 a 1.00 & Excelente \\
\hline
\end{tabular}

\section{MATERIAL E MÉTODOS}

\section{1 Área de estudo}

A Bacia do Rio Vieira (Fig. 1) está totalmente inserida no perímetro do município de Montes Claros, sendo o Rio Vieira, a principal rede hidrográfica do município.

Fonte: Landis e Koch (1977).

\section{Localização da Bacia do Rio Vieira}

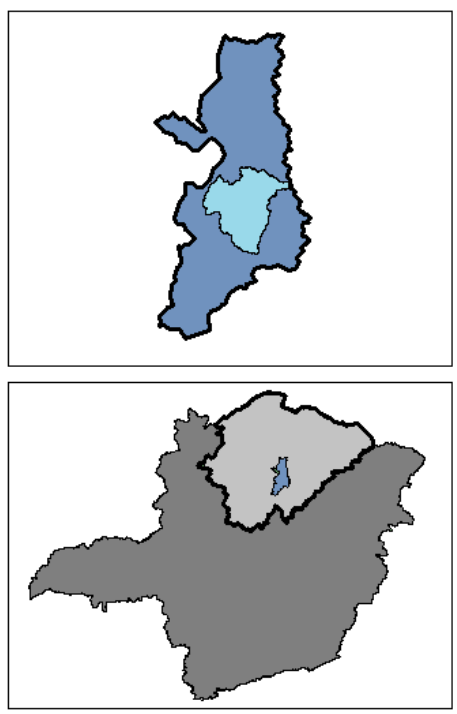

Bacia do Rio Vieira

Montes Claros

Norte de Minas Gerais

Minas Gerais

DATUM: SIRGAS 2000

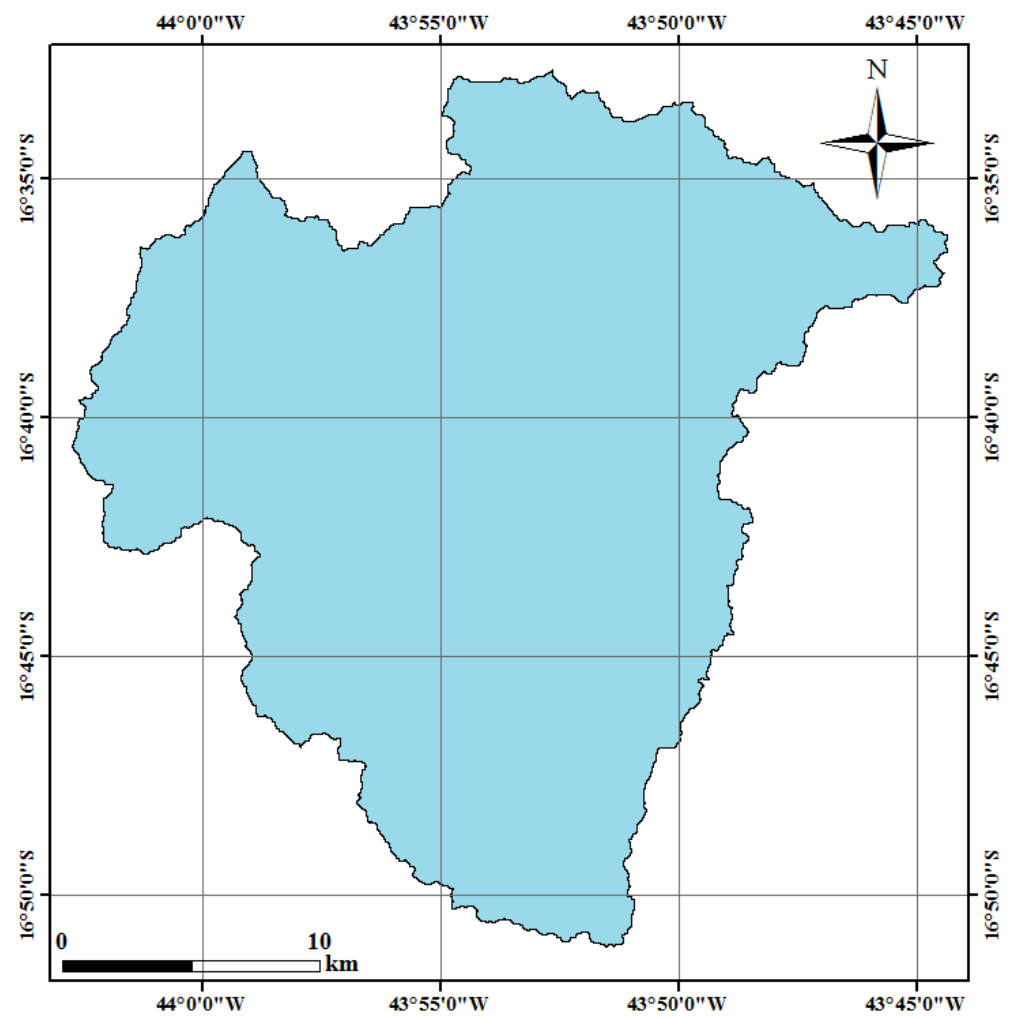

Figura 1 - Localização da Área de Estudo. Fonte: Próprio Autor.

Montes Claros se localiza ao Norte do Estado de Minas Gerais, compreendido entre as latitudes $16^{\circ}$ $5^{\prime} 31.38^{\prime \prime S}$ e $17^{\circ} 9^{\prime} 1.07^{\prime \prime S}$ e longitudes $43^{\circ} 46^{\prime} 3.75^{\prime \prime} \mathrm{W}$ e $44^{\circ}$ $6^{\prime} 30.79^{\prime \prime} \mathrm{W}$, possui cerca de 361.915 habitantes em unidade territorial de $3.568,941 \mathrm{~km}^{2}$, está a cerca de 418 Km da capital Belo Horizonte (IBGE, 2010). Possui clima tropical semi-úmido, Aw na classificação Köppen, temperatura média anual de $24^{\circ} \mathrm{C}$ e índice médio pluviométrico anual de $1.074 \mathrm{~mm}$. Predomina como formas de vegetação, o cerrado caducifólio com manchas de mata seca, e trechos de transição com a caatinga (FRANÇA; SOARES, 2007, NERY et al., 2013).

$\mathrm{O}$ Rio Vieira tem sua nascente localizada entre as coordenadas $43^{\circ} 56^{\prime} 04^{\prime \prime}$ 'W de longitude e $16^{\circ} 47^{\prime} 22^{\prime}$ ' S de latitude, na antiga fazenda Vieiras, a cerca de 8 quilômetros da cidade de Montes Claros, é um afluente do
Rio Verde Grande, bacia federal, tributária da margem direita do Rio São Francisco. Visto a importância do Rio Vieira como contribuinte de uma bacia federal, podendo interferir em sua qualidade, conduzindo carga poluidora recebida ao longo do seu percurso (VELOSO; NERY, 2011; BORGES, 2007; FONSECA; FONSECA, 2012).

O Rio Vieira, em decorrência de diversas pressões exercidas pelas atividades antrópicas ao longo do tempo, sofreu uma ampla descaracterização da sua paisagem, cercado de edificações e aglomerações, substituindo a vegetação e constituintes da paisagem natural (FONSECA; FONSECA, 2012).

De acordo com Borges (2007), a desarmonia das relações entre a cidade de Montes Claros com o seu recurso hídrico, tem abrangência externa, causando 
contaminação das águas do Rio Verde grande, afluente do Rio São Francisco.

\subsection{Procedimento metodológico}

Seguindo metodologia aplicada por Lima et al. (2012), utilizou-se de dados altimétricos da cena 16S45_ZN dos dados SRTM (Shuttle Radar Topographic Mission), disponível no projeto TOPODATA para a delimitação automática de Bacia Hidrográfica do Rio Vieira, utilizando a plataforma TerraHidro, que é um aplicativo do SIG TerraView.

$\mathrm{Na}$ fase de processamento, utilizou-se de imagem do sensor LISS3, acoplado ao satélite ResourceSat-1 de órbita e ponto 329-089 da data de 16 de dezembro de 2012, disponível gratuitamente no site do Instituto Nacional de Pesquisas Espaciais (INPE).

Com a aquisição da imagem de interesse, realizou-se o registro desta utilizando o software ENVI 5.0, tendo como referência a imagem ortorretificada TM/Landsat-5 de órbita e ponto 218-072 do ano de 2006.

Posteriormente foi criado um banco de dados no SPRING 5.2.2, onde o perímetro da bacia e a imagem do sensor LISS3 foram importados.

A etapa de classificação, teve o trabalho desenvolvido por Leite et al. (2011), como base metodológica. Desta forma, a classificação foi realizada utilizando de classificação supervisionada, pixel a pixel, classificador, máxima verossimilhança (MAXVER) com limiar de aceitação 99,99\%.

Foram definidas as mesmas classes utilizadas por Leite et al. (2011), no mapeamento da bacia do Rio Vieira em 2009, apenas acrescentando a classe de recursos hídricos.
Para determinação da acurácia do mapa temático do ano de 2012 gerado a partir da classificação empregada, foi utilizado o índice Kappa derivado da matriz de confusão.

O mapa obtido do mapeamento do uso e ocupação da Bacia do Rio Vieira em 2012 foi desenvolvido no ArcGIS 10.

A utilização dos softwares ENVI 5.0 e Arc Gis 10 neste trabalho foi sob Licença do Laboratório de Topografia, Cartografia e Geoprocessamento (LABGEO), das Faculdades de Ciências Exatas e Tecnológicas Santo Agostinho.

\section{RESULTADOS E DISCUSSÃO}

A partir do mapeamento proposto por Leite et al. (2011) no mapa de uso do solo do ano de 2009 (Fig. 2), os autores encontraram em seus resultados, uma área de vegetação natural de $293 \mathrm{~km}^{2}$, essa extensa área de vegetação preservada, é atribuída pelos autores, à criação de três parques no município de Montes Claros, os parques municipais, Sapucaia e Guimarães Rosa e o parque estadual da Lapa Grande. Já neste trabalho, no mapeamento da Bacia do Rio Vieira em 2012 (Fig. 3), utilizando mesma metodologia, obteve uma área de $324,95 \mathrm{~km}^{2}$ de vegetação preservada, que significa um aumento de $5,11 \%$ em três anos. 


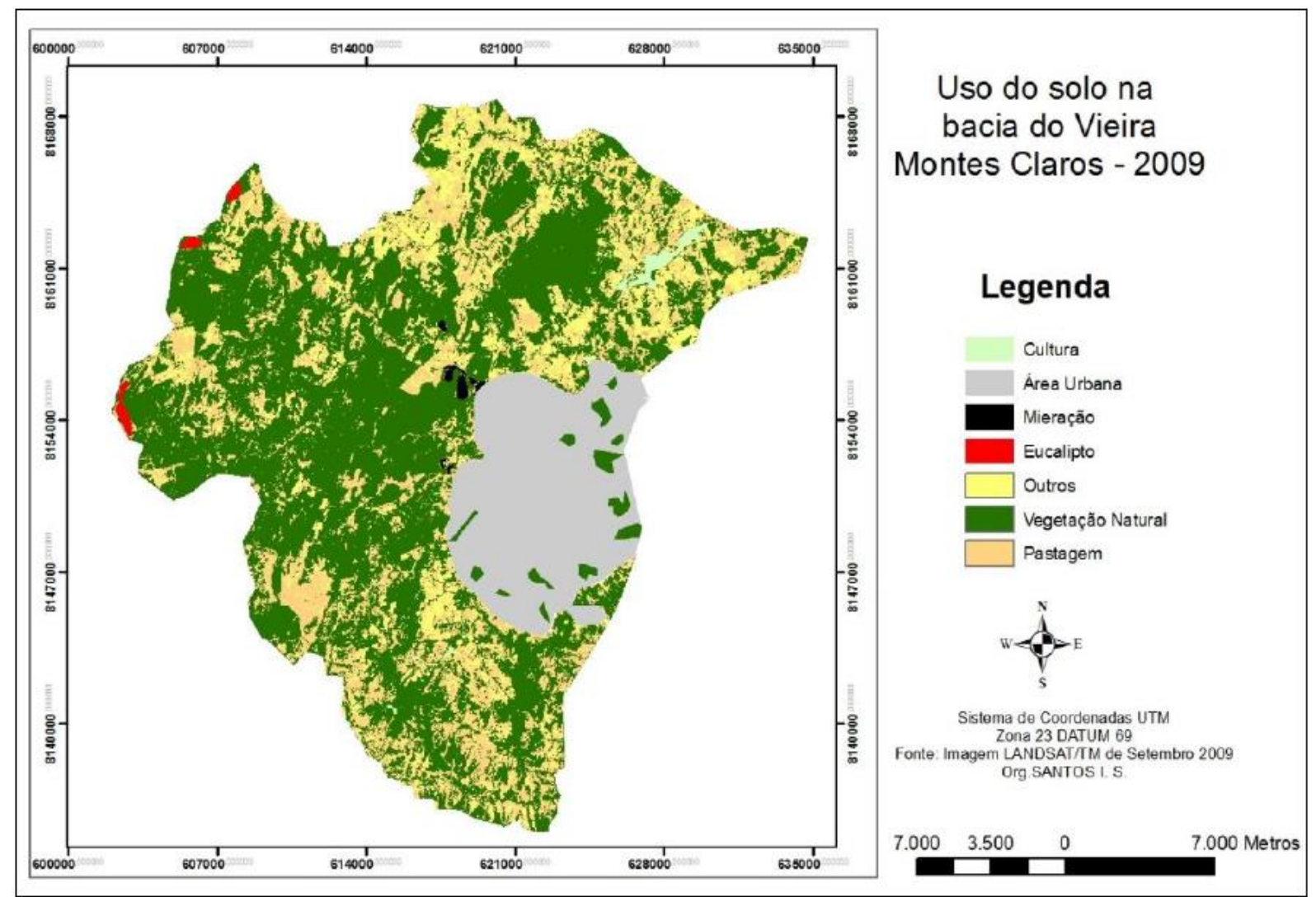

Figura 2 - Uso do solo na bacia do rio Viera em 2009.

Fonte: Leite et al. (2011).

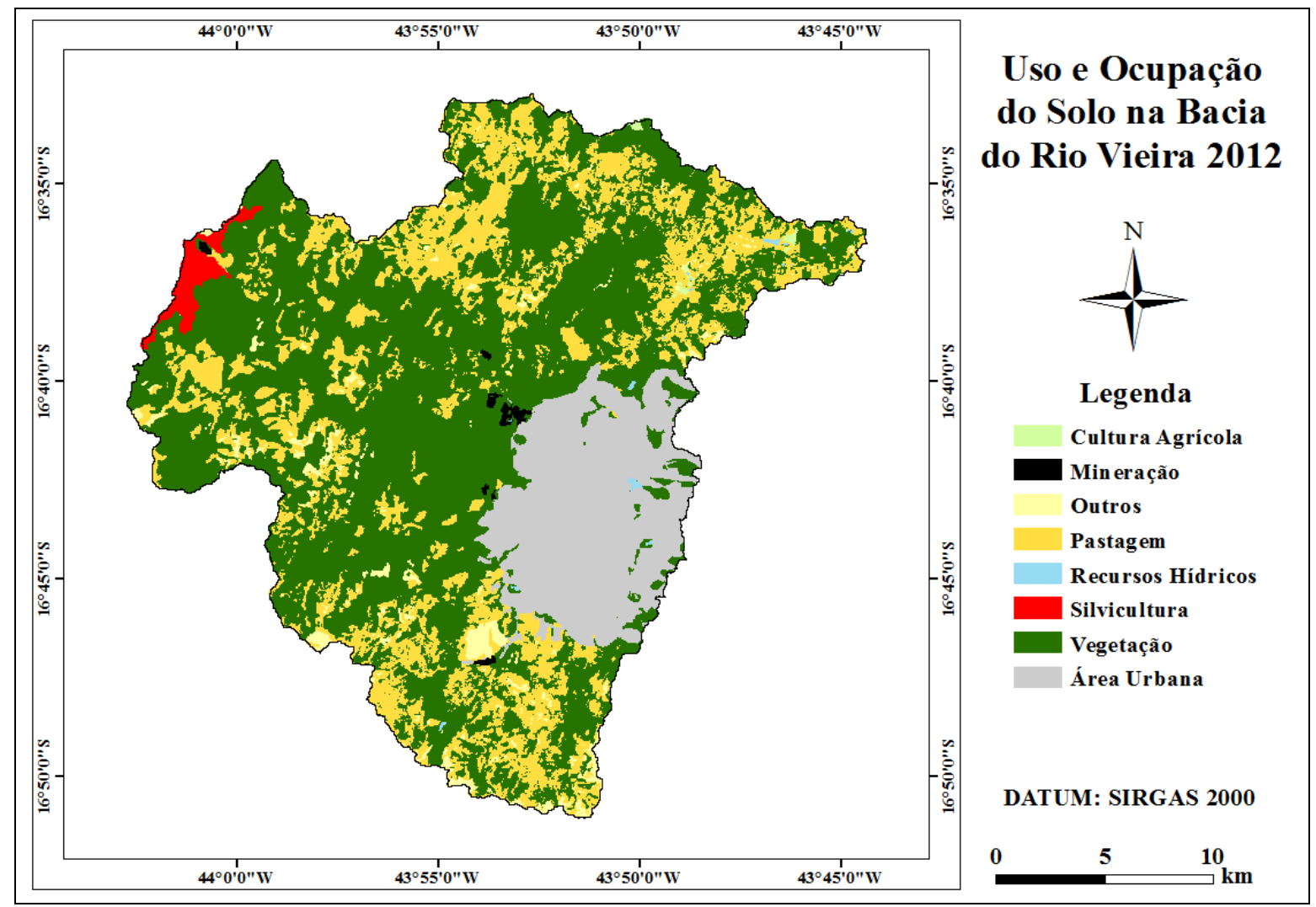

Figura 3 - Uso e Ocupação do solo 2012.

Fonte: Próprio Autor 
A maior representatividade da vegetação natural na Bacia do Rio Vieira pode ser atribuída às formas do terreno, que dificulta o seu uso para agricultura e pecuária, uma vez que conforme nota técnica do Ministério de Minas e Energia (2009), no Norte de Minas, a porção elevada do terreno, é constituída por morros de calcário, pertencentes ao planalto residual do São Francisco; na porção baixa é plana, denominada depressão São Franciscana. O revelo é caracterizado em maior ocorrência por feições onduladas, as feições planas e montanhosas juntas constituem cerca de $40 \%$ do relevo local.

Em 2009, a bacia do Rio Vieira, possuía uma área de pastagem equivalente a $132 \mathrm{~km}^{2}$, em 2012 essa classe teve um aumento de 1,47\% com uma área de $142,02 \mathrm{~km}^{2}$.

Quanto à área urbana, em 2009 essa classe apresentou uma área de $86 \mathrm{~km}^{2}$ Leite et al. (2011) e em 2012 obteve se $86,04 \mathrm{~km}^{2}$, é importante destacar que os recursos hídricos não foram classificados pelos autores no ano de 2009, todavia na Bacia do Rio Vieira, estes correspondem a $0,89 \mathrm{~km}^{2}$ de área ocupada, inclusive inseridos na classe área urbana.

De acordo com a pouca variação da classe área urbana no período analisado, vale ressaltar que apesar do aquecimento do setor da construção civil nos últimos anos em Montes Claros, esta praticamente não sofreu variação, muito devido ao perfil das novas edificações na cidade, pois, estão sendo priorizada nesse setor a construção de condomínios e prédios, assim sendo, observa-se na cidade um maior crescimento vertical.

O uso do solo para mineração obteve um aumento 0,07\% de 2009 para 2012. A mineração tem ganhado espaço no Norte de Minas nos últimos anos, de acordo com Nunes et al. (2012), a região é considerada a nova província minerária do Estado, encontrando em fase de implantação projetos de exploração de minérios e ainda, dentro do perímetro da bacia, existem títulos minerários em fase de pesquisa, licenciamento e com autorização de lavra. Os títulos minerários da Bacia do Rio Vieira são principalmente para exploração dos minerais de argila e calcário.

A silvicultura em 2012 apresenta uma área de 6,76 $\mathrm{km}^{2}$, ao passo que em 2009 era apenas $1,6 \mathrm{~km}^{2}$. Conforme Pereira et al. (2009), a silvicultura é uma das principais atividades econômicas do Norte de Minas e dos vales do Jequitinhonha e Rio Doce. No Norte de Minas, o cultivo de eucalipto, produz além do carvão vegetal, ainda dois outros subprodutos importantes para a economia regional; a produção de folha de eucalipto e a de resina. Sendo a região, a única no Estado a produzir folhas de eucalipto com destinações comerciais.

A cultura agrícola, ao contrário da silvicultura, teve um decréscimo de $-2,64 \%$ em 2012, porém é válido observar, que em função da resolução da imagem LISS3/ResourceSat-1, houve dificuldades no mapeamento dessa classe, pois suas áreas na Bacia do Rio Vieira, são de pequenas extensões e se confundem com outras classes, como de vegetação natural e pastagem, de acordo com o tipo de cultura, pode-se então, mapear, somente aquelas com maiores áreas.

A classe "outros", que foi definida por Leite et al. (2011), como aquela correspondente a espaços ocupados por diversos usos do solo, tendo então, conflito na resposta espectral, apresentou em 2012 uma área de 1483 $\mathrm{km}^{2}$, em 2009 foram $40 \mathrm{~km}^{2}$. Esse decréscimo da classe pode ser atribuído, a menor confusão da resposta espectral.

A Tab. 2, a seguir, demonstra os dados quantitativos da aplicação da metodologia proposta nos dois períodos analisados.

Tabela 2 - Resultados do uso e ocupação do solo na bacia do rio Vieira em 2009 e 2012.

\begin{tabular}{cccccc}
\hline Classes & \multicolumn{2}{c}{ Ano 2009 } & \multicolumn{2}{c}{ Ano 2012 } & Variação (\%) \\
\hline & Área Km ${ }^{2}$ & Área (\%) & Área Km & Área (\%) & $-0,22$ \\
Área Urbana & 86 & $15,10 \%$ & 86,04 & $14,88 \%$ & $-2,64$ \\
Cultura Agrícola & 16 & $2,80 \%$ & 0,95 & $0,16 \%$ & 0,88 \\
Silvicultura & 1,6 & $0,28 \%$ & 6,76 & $1,16 \%$ & 0,07 \\
Mineração & 1,4 & $0,25 \%$ & 1,86 & $0,32 \%$ & 1,47 \\
Pastagem & 132 & $23,10 \%$ & 142,02 & $24,57 \%$ & 5,11 \\
Veg. Natural & 293 & $51,10 \%$ & 324,95 & $56,21 \%$ & $-4,54$ \\
Outros & 40 & $7,10 \%$ & 14,83 & $2,56 \%$ & - \\
R. Hídricos & - & - & 0,89 & $0,15 \%$ & -
\end{tabular}


A Fig. 4 abaixo apresenta os valores das classes mapeadas na Bacia do Rio Vieira no ano de 2012.

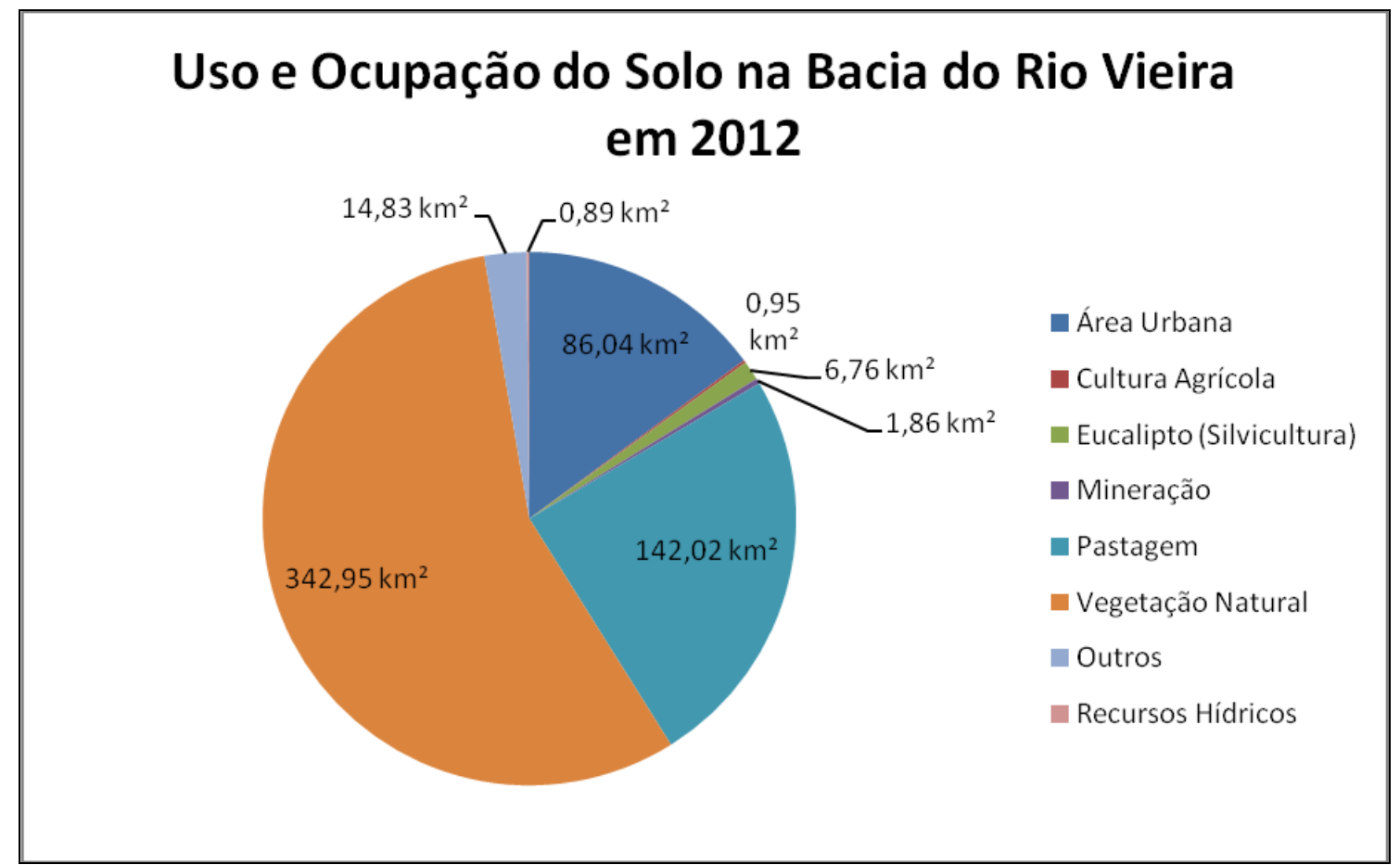

Figura 4 - Gráfico do uso das classes na Bacia do Rio Vieira no ano 2012.

Fonte: Próprio Autor.

De acordo com o gráfico a seguir (Fig. 5), é possível verificar a variação das classes de uso da Bacia do Rio Vieira no período analisado.

Os resultados da concordância do índice Kappa utilizado para avaliar a classificação do ano de 2012, foi de 0,75 o que considera se forte de acordo com os intervalos de concordância do índice de Kappa (LANDIS; $\mathrm{KOCH}, 1977)$.

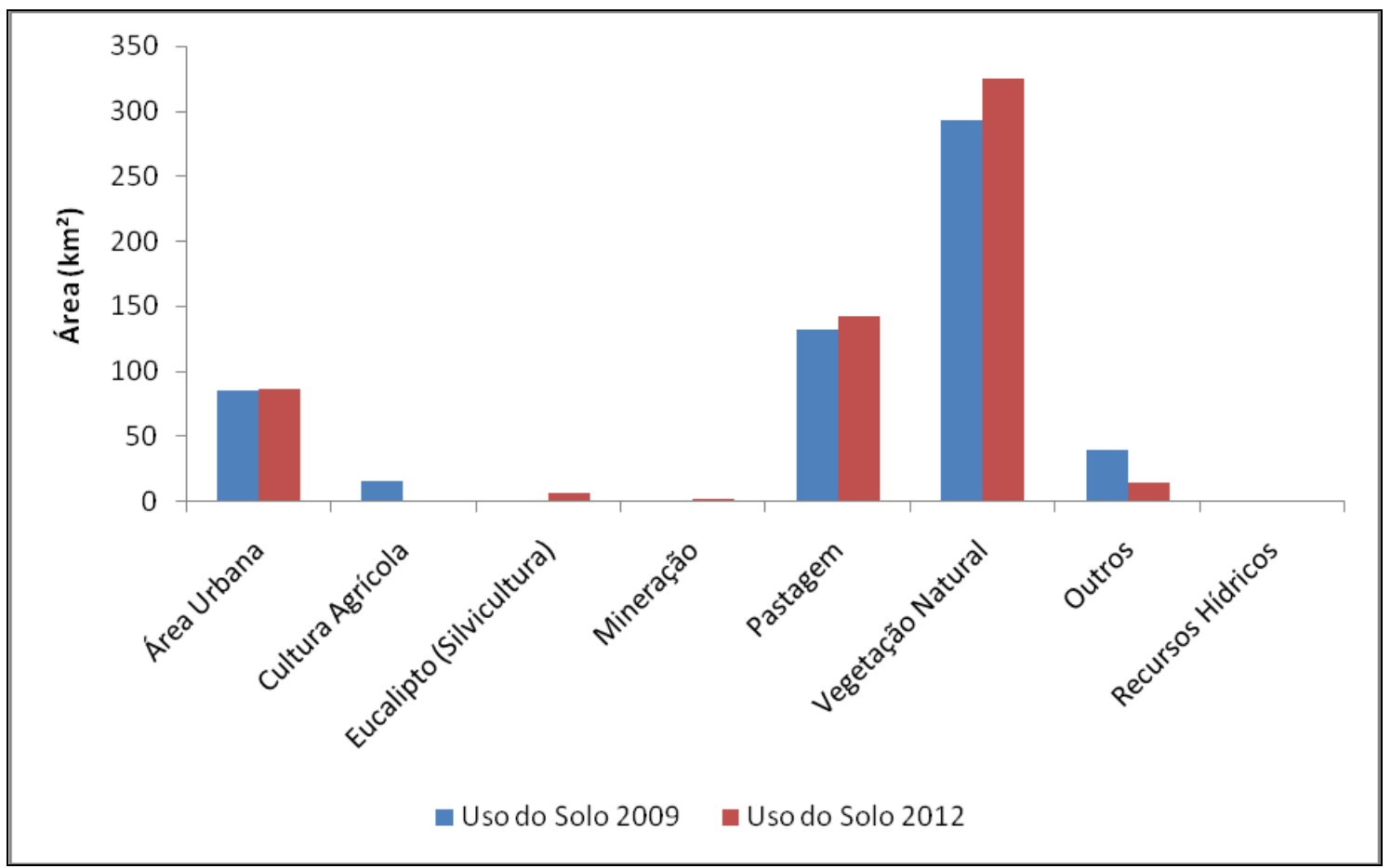

Figura 5 - Gráfico comparativo do uso das classes na Bacia do Rio Vieira no ano de 2009 e 2012. Fonte: Próprio Autor. 


\section{CONCLUSÃO}

A metodologia aplicada possibilitou o mapeamento dos usos do solo na Bacia do Rio Vieira, em Montes Claros/MG em um intervalo de análise de três anos. Nos resultados obtidos através do mapeamento do uso e ocupação do solo, infere-se que a maior parte da área ainda é ocupada por vegetação natural, devido a morfologia acentuada da região. Apesar do aumento de vegetação natural, ainda foi possível constatar que existem $24,92 \%$ do total da área de pastagem, na bacia do Rio Vieira, pois a pecuária é uma atividade econômica muito representativa no Norte do Estado de Minas Gerais.

As técnicas de sensoriamento remoto mostraram se eficientes, pois possibilitaram a comparação das transformações ocorridas na unidade de gestão do Rio Vieira entre o ano de 2012 com o estudo desenvolvido por Leite et al. (2011) do ano de 2009. A silvicultura, atividade econômica muito representativa no Norte de Minas, teve crescimento entre os períodos analisados, assim como a atividade de mineração, que teve um aumento considerável na região. No entanto, a cultura agrícola e a classe outros apresentaram reduções significativas durante o período analisado.

O resultado do uso de geotecnologias para elaboração de mapas temáticos com alto grau de acurácia foi satisfatório, subsidiando informações que foram suficientes para a avaliação das classes da bacia, bem como o uso delas. Essas informações obtidas podem ser usadas pelos gestores, a fim de buscar soluções capazes de satisfazer o uso sustentável dos recursos naturais da bacia do Rio Vieira.

\section{AGRADECIMENTOS}

Os autores agradecem a Fundação Santo Agostinho e ao CNPq pelo apoio e incentivo.

\section{REFERENCIAS BIBLIOGRÁFICAS}

BORGES, L. (2007). Qualidade da Água do Rio Vieira Sob a Influência da Área Urbana de Montes Claros - MG. Dissertação (Mestrado). Universidade Federal de Urbelândia. Urbelândia - MG. Disponível em <http://repositorio.ufu.br/handle/123456789/433> Acesso em 20 de Março de 2013.

BRASIL. Lei $\mathrm{n}^{\circ}$ 9.433, de 8 de Janeiro de 1997 - Política Nacional de Recursos Hídricos. Disponível em <http://www.planalto.gov.br/ccivil_03/leis/L9433.htm> Acesso em: 05 mar. 2013.

CÂMARA, G.; SOUZA, R.C.M.; FREITAS, U. M.; GARRIDO, J. C. P. (1996). SPRING: Integrating Remote Sensing and GIS with Object-Oriented Data Modelling. Computers and Graphics, v.15, n.6, p.13-22. Disponível em<http://www.dpi.inpe.br/geopro/trabalhos/spring.pdf> Acesso em 12 de Fevereiro de 2013.
CASTANHEIRA, L. A. (2010). Estudo das Mudanças de Uso e Cobertura da Terra no Parque Nacional da Serra do Cipó e Entorno no Período de 1989 a 1999. Dissertação (Mestrado). UFMG - Universidade Federal de Minas Gerais. Belo Horizonte - MG. Disponível em <http://www.csr.ufmg.br/modelagem/dissertacoes/luiz_art ur_castanheira.pdf> Acesso em 30 de Março de 2013.

CUNHA, K. L.(2009). Uso de Imagens Landsat e CBERS no Mapeamento da Suscetibilidade à Erosão na Região de Primavera do Leste - MT. Dissertação (Mestrado). UFMT - Universidade Federal de Mato Grosso do Sul. Mato Grosso do Sul - MT. Disponível em $<$ http://www.pgfa.ufmt.br/index.php?option=com_docma n\&task=doc_download $\&$ gid $=134 \&$ Itemid $=37>\quad$ Acesso em 02 de Abril de 2013.

DILL, P. R. J. (2007). Gestão Ambiental em Bacias Hidrográficas. Tese (Doutorado). UFMS - Universidade Federal de Santa Maria. Santa Maria - RS. Disponível em <http://www.dominiopublico.gov.br/pesquisa/DetalheObr aForm.do?select_action $=\&$ co_obra $=117932>$ Acesso em 23 de Abril de 2013.

FONSECA, V. L.; FONSECA, G. S. (2012). A Paisagem de agonia do Rio Vieira em Montes Claros- MG. UNIMONTES - Universidade Estadual de Montes Claros - MG. Montes Claros - MG. Disponível em < http://www.unimontes.br/arquivos/2012/geografia_ixerg/e ixo_politica_meio_ambiente/a_paisagem_de_agonia_do_r io_vieira_em_montes_claros.pdf $>$ Acesso em 23 de Abril de 2013.

FITZ, P. R. (2008). Geoprocessamento sem complicação. São Paulo: Oficina de Textos. 97129.

FLORENZANO, T. G. (2011). Iniciação em Sensoriamento Remoto. 3. ed. São Paulo - SP: Oficina de Textos.

FRANÇA, I. S.; SOARES, B. R.(2007). Expansão Urbana em Cidades Médias: Uma reflexão a partir do núcleo e da área central de Montes Claros no Norte de Minas Gerais. Geo UERJ - Ano 9, $\mathrm{n}^{\circ}$ 17, vol. 2. Disponível em < http://www.epublicacoes.uerj.br/index.php/geouerj/article/viewFile/13 05/1102> Acesso em 24 de Março de 2013.

IBGE - Instituto Brasileiro de Geografia e Estatística. Censo 2010. Disponível em <http://www.ibge.gov.br/cidadesat/topwindow.htm?1> Acesso em 04 de Março de 2013.

LEITE, M. E.; SANTOS, I. S.; ALMEIDA, J. W. L. (2011). Mudança de Uso do Solo na Bacia do Rio Vieira, em Montes Claros/MG. Revista Brasileira de Geografia Física 04, p. 779-792. Disponível em 
<http://www.revista.ufpe.br/rbgfe/index.php/revista/articl e/view/199/266> Acesso em 23 de Março de 2013.

LIMA, F. A.; ALMEIDA, L. S.; BRAGA, F. L.; NERY, C. V. M. (2012). Utilização do Sistema de Informações Geográficas TerraView para Delimitação da Bacia Hidrográfica do Rio Vieira, Montes Claros - MG. VI GEONORDESTE - Simpósio Regional de Geoprocessamento e Sensoriamento Remoto. Aracaju SE. Disponível em < http://www.cvmn.com.br/HTML/Arquivos/Artigos/00220 _025704.pdf> Acesso em 24 de Março de 2013.

LIU, W. T. H. (2006). Aplicações de Sensoriamento Remoto. Campo Grande-MS: UNIDERP.

LANDIS, J.; KOCH, G.(1977). The measurement of observer agreement for categorical data, Washington, USA. Biometrics, v. 33, n. 1, p. 159-174. Disponível em <http://www.jstor.org/discover/10.2307/2529310?uid=2\& uid=4\&sid=21102991969287> Acesso em 23 de Abril de 2013.

MARTE, C. L.; QUINTANILHA, J. A.; RODRIGUES, M. (2011). Atividade Prática: Laboratório de Classificação Supervisionada de Imagens de Sensoriamento Remoto Exercício: Aeroporto Guarulhos. Escola Politécnica de Universidade de São Paulo. São Paulo - $\quad$ SP.Disponível em < http://pt.scribd.com/doc/54638738/Roteiro-SR-4> Acesso em 12 de Fevereiro de 2013.

MME - Ministério de Minas e Energia. (2009). NOTA TÉCNICA DEA 04/09: Análise socioambiental de alternativas para o atendimento à Interligação Pirapora Montes Claros. EPE: Rio de Janeiro - RJ. Disponível em <http://www.epe.gov.br/MeioAmbiente/Documents/Estud os $\% 20$ socioambientais $\% 20 \mathrm{de} \% 20$ expans $\% \mathrm{C} 3 \% \mathrm{~A} 3 \mathrm{o} \% 20$ da\%20transmiss\%C3\%A3o/Interliga\%C3\%A7\%C3\%A3 o\%20Pirapora\%20\%E2\%80\%93\%20Montes\%20Claros\% 20-\%20Relat\%C3\%B3rio-R1.pdf> Acesso em 22 de Fevereiro de 2013.

NERY, C. V. M.; FERNANDES, F. H. S.; MOREIRA, A. A.; BRAGA, F. L. (2013). Avaliação das Técnicas de Classificação MAXVER, MAXVER - ICM e Distância Mínima Euclidiana de acordo com Índice Kappa. Revista Geografia Física. V. 6, n.2, p. 320-328.

NOVO, E. M. L. M. (2010). Sensoriamento Remoto Princípios e Aplicações. 4. ed. São Paulo -SP: Blucher.

NUNES, M. A. J.; COSTA, S. G.; SILVA, R. G.(2012). O Quadrilátero Ferrífero e o Norte de Minas Gerais: Análise da História e Importância Econômica. Disponível em<http://www.camat.unimontes.br/arquivos/2012/geogr afia_ixerg/eixo_politica_meio_ambiente/o_quadrilatero_f errifero_e_o_norte_de_minas_gerais_analise_da_historia _e_import\%C3\%82ncia_econ\%C3\%94mica.pdf> Acesso em 07 de Março de 2013.
PEREIRA, A. A.; NOGUEIRA, A. H.; OLIVEIRA, M. C. (2009). Politicas Públicas e Financiamento no Setor Florestal: Oportunidades de Negócios para Pequenas e Médias empresas e/ou produtores. Disponível em < http://www.indi.mg.gov.br/img/estudos/85Artigo\%20Silv icultura.pdf $>$ Acesso em 28 de Fevereiro de 2013.

PHILIPPI, A. J.; ROMÉRO, M. A.; BRUNA, G. C. (2005). Curso de Gestão Ambiental. Universidade de São Paulo, Barueri - SP.

VELOSO, A. R.; NERY, C. V. M. (2011). Geoprocessamento aplicado à caracterização do Parque da Lapa Grande em Montes Claros/MG. 2011. XV Simpósio Brasileiro de Sensoriamento Remoto - SBSR, Curitiba PR, Brasil, INPE p.3711. Disponível em < http://www.dsr.inpe.br/sbsr2011/files/p0706.pdf> Acesso em 12 de Fevereiro de 2013. 